\title{
Práticas educativas e metodológicas inovadoras para uma Educação Jurídica no âmbito da Rede Federal de Educação Profissional e Tecnológica
}

\section{Educational practices and innovative methodologies for Legal Education within the Federal Network of Professional and Technological Education}

\author{
Nick Andrew Pereira Ugalde (1D https://orcid.org/0000-0002-1423-1489 \\ Instituto Federal de Educação, Ciência e Tecnologia do Acre \\ e-mail - nick.ugalde@ifac.edu.br \\ João Ricardo Avelino Leão (D) https://orcid.org/0000-0002-0669-4715 \\ Instituto Federal de Educação, Ciência e Tecnologia do Acre \\ e-mail - joao.aleao@ifac.edu.br
}

Cleilton Sampaio de Farias (iD https://orcid.org/0000-0003-1783-3175

Instituto Federal de Educação, Ciência e Tecnologia do Acre

e-mail - cleilton.farias@ifac.edu.br

\section{Resumo}

Este artigo tem por objetivo caracterizar e discutir práticas educativas no âmbito da educação jurídica prestada pela Rede Federal de Educação Profissional, Científica e Tecnológica, incluindo metodologias ativas inovadoras associadas. Para tal fim, realizou-se estudo com abordagem qualitativa, visando à compreensão de aspectos do objeto, contexto, ambientes e resultados, utilizando pesquisa documental e revisão bibliográfica como principais procedimentos, com identificação de periódicos e artigos por meio de descritores de busca, bem como análise de trabalhos vinculados ao Mestrado Profissional em Educação Profissional e Tecnológica (ProfEPT) e sobre a temática. Os resultados apontam para necessidade de formação jurídica no ensino médio integrado, contribuindo para formação cidadã e ética, com elementos de criticidade, autonomia e maior interação.

Palavras-chave: Educação profissional. Práticas educativas. Ensino de direito.

\begin{abstract}
The objectives of the present work are to characterize and discuss the educational practices adopted in law education in the Federal Network of Professional, Scientific, and Technological Education, with their active and innovative teaching methodologies. Thus, the research used a qualitative approach, to understand the aspects of the object, context, places, and results. The procedures were based on documentary research and bibliographical review, applying, for the last one, specific descriptors to find academic journals and articles. Besides that, were studied some couples of thesis and educational products developed on Professional Master in Professional and Technological Education about this research theme. The results indicate the need for law education in high school, contributing to ethic and citizenship education, with criticality elements, autonomy, and major interaction.
\end{abstract}


Keywords: Professional education. Educational practices. Law related education.

\section{Introdução}

A educação brasileira, a despeito da inequívoca melhoria no seu alcance e quanto a novos arranjos e modelos, tem apresentado resultados ruins em exames de proficiência aceitos em âmbito internacional, regional e de blocos de países, e também no contexto das avaliações de larga escala levadas a cabo em seu território, as quais foram desenvolvidas para os níveis formais previstos na Constituição e na legislação de ensino (PIERI, 2018).

Nesse sentido, cabe detalhar o cenário do magistério jurídico, iniciando da formação acadêmica de nível superior de bacharelado em Direito para, após breves análises, reflexões e críticas, aprofundar sobre perspectivas da educação jurídica ofertada pela Rede Federal, de modo a possibilitar inferências para o ensino da área em disciplinas ou conteúdos dos cursos técnicos, especialmente naqueles do tipo ensino médio integrado (EMI) à educação profissional e tecnológica.

No âmbito do ensino jurídico, na linha de Ferraz Júnior (2016), relevância maior tem sido atribuída à zetética jurídica, considerada enquanto enfoque especulativo sobre as opções do dever-ser, com infinitas possibilidades enquanto questionamentos, ao passo que a dogmática é vista como área posta do Direito, em que residem as decisões ou escolhas já tomadas e que são aplicadas por meio da subsunção jurídica ou da norma ao fato, vale dizer, aplicar aquilo que está descrito na lei às situações do cotidiano.

O magistério jurídico caminha sobre um espaço em que se pode privilegiar questões filosóficas relacionadas a outras áreas de saber, ao que o Direito integra-se às questões sociais, sem descuidar da necessidade de saber as "regras do jogo"; ou fazer um ensino repetitivo e estritamente centrado na aquisição de competências mais básicas ou relacionadas a questões conceituais e memorizações de dispositivos de normas, cuja execução atualmente mostra-se incompatível para estudantes mais jovens, conforme apontado por Amaral e Rocha (2019).

Dessa forma, há que se pleitear um ensino realmente integrado ao cotidiano, ou seja, que parta da realidade concreta dos alunos (a incluir conhecimento sobre suas dificuldades), que retire docente e estudantes de uma zona de conforto estabelecida há tempos pelos métodos tradicionais de aulas expositivas, que inclua metodologias participativas e atividades extracurriculares nas quais se deixem claras as conexões entre o que se vive e o que se trabalha em sala de aula ou mesmo percebe-se fora dela (ALMEIDA; SOUZA; CAMARGO, 2013).

Nesse sentido, a busca por processos e condições didáticas que assegurem uma apreensão e apropriação de conteúdos, incluídos os de natureza mais técnica, exige uma variabilidade pedagógica, ao que se revisita a teoria de aprendizagem receptiva significativa de David Ausubel, conforme descrita em Ausubel, Novak e Hanesian (1980), em que o processo cognitivista de aprendizagem demanda o aproveitamento de um elemento isolado que é o conhecimento pré-existente, o qual, na teoria de Ausubel, é definido como subsunçor (âncora necessária para novos aprendizados e desenvolvimento ou alteração de conceitos). 
O processo estimulante e motivador dependeria em parte das habilidades para promover formas diversificadas de ensinar e poderia ser conjugado com a técnica de elaboração de Mapas Conceituais (MC) de Novak e Canãs (2010), que Moreira (2011) conceitua dentro da ideia de recurso vinculado a cada unidade de ensino potencialmente significativa (UEPS).

Assim, as dificuldades relacionadas aos processos de ensinar e aprender em cursos superiores de Direito demandou a introdução de tecnologias de uso frequente e de amplo domínio por estudantes (em sua maioria), conforme enfatizado por Amaral e Rocha (2019) e movimentos de vai e vem entre pesquisa, ensino e extensão (MELO, 2018), repercutindo em participação, criação, autonomia e ganhos sociais, pessoais e institucionais.

Nesse cenário, as metodologias ativas, como ensinam Bacich e Moran (2018), são caracterizadas pelo protagonismo do estudante que, figurando no centro do processo, interage e atua de maneira decisiva na construção do percurso, responsabilizando-se por criar, pesquisar, aplicar e executar demais atividades inerentes ao processo de ensino-aprendizagem contextualizado, tudo sob a supervisão do professor.

Destarte, este artigo objetivou discutir questões associadas ao atual cenário da educação, em especial do magistério jurídico, inserindo-o dentro da oferta de educação jurídica no âmbito da Educação Profissional e Tecnológica (EPT) a cargo da Rede Federal de Educação Profissional, Científica e Tecnológica, composta majoritariamente por Institutos Federais de Educação, Ciência e Tecnologia (IFs).

Para este fim, organizou-se o texto em seções que, para além desta, incluem uma discussão sobre a RFEPCT, a título de referencial teórico da pesquisa; detalhamento de materiais e método utilizados para alcançar o objetivo, e culminando com os resultados e discussão com foco no ensino jurídico na referida rede, utilizando-se da análise de trabalhos produzidos por egressos do ProfEPT e voltados para a educação jurídica, de tudo fazendo-se apanhado sintético na seção de considerações finais.

\section{Perspectiva de ensino na Rede Federal de Educação Profissional e Tecnológica}

A Rede Federal surge para equacionar problemas sociais e demandas reprimidas há tempos, especialmente quando se pensa no ensino médio ou na educação antes intitulada secundária (MESQUITA; LELIS, 2015), ao que o art. $8^{\circ}$ da Lei $n^{\circ}$ 11.892/2008 (lei de criação da rede) vai exigir a destinação de um mínimo de 50\% (cinquenta por cento) das vagas de cada instituição para a "educação profissional técnica de nível médio, prioritariamente na forma de cursos integrados, para os concluintes do ensino fundamental e para o público da educação de jovens e adultos" (BRASIL, 2008).

A nomenclatura e suas bases fundamentam-se nos eixos da vida humana preconizados por Marx, conforme cita Moura (2013), quais sejam: trabalho, ciência, tecnologia e cultura, de modo a promover uma educação de cunho humanista, pois pensada para o ser humano e suas necessidades maiores, e não para um segmento, elemento ou fator de produção, a exemplo de uma exclusiva preparação para o mercado de trabalho. 
Ainda conforme Moura (2013), trabalha-se ciência e tecnologia enquanto apanhados e acúmulos sociais decorrentes da experimentação, da verificação e da utilização dos métodos e técnicas, bem como estudos sobre suas aplicabilidades dentro de contextos sociais próprios, conduzindo à formação da cultura, enquanto valores construídos e cultivados.

Não obstante tais objetivos da Rede, Mesquita e Lelis (2015) relacionam problemas no aludido nível de ensino relacionados com infraestrutura, remuneração e formação docente, bem como escassez de políticas públicas norteadoras para o citado nível de educação formal, ao que também promovem uma discussão sobre a perspectiva que se tem para o uso do ensino e das aprendizagens nele geradas, bem como sobre as complexidades e avaliações enquanto elementos que impactam a permanência.

Seguindo, esclarecem que o ensino médio deve atender a demandas dos jovens, pautadas em vivências e experimentações, e na realidade ou nas projeções que Ihes são permitidas, considerando realidades e demandas sociais, a exemplo da possibilidade de acesso ao ensino superior e da premente necessidade de ingresso em mercado de trabalho para grupos com menor faixa de renda, em cujas famílias o trabalho do jovem torna-se um elemento fundamental para a sobrevivência.

Nesse contexto, a Rede Federal presta educação profissional e técnica de nível médio, por meio de cursos enquadrados nos eixos catalogados pelo Ministério da Educação, com currículos compostos por disciplinas as mais diversas, inclusive jurídicas, as quais são ministradas por professores, mais das vezes, bacharéis em Direito, alguns sem experiência prévia com a docência e formação pedagógica, ou, ao menos, no segmento da educação profissionalizante.

A matriz teórica que deu origem à Rede Federal de Educação Profissional, Científica e Tecnológica é marxista, ao que conceitos basilares transparecem e formam a base de análise para a proposta formulada, no sentido de tratar de um tipo especial de educação, a profissional (KUENZER; GRABOWSK, 2016), epistemologicamente concebida como educação para um determinado grupo social, em que se tenta superar a dicotomia formação para o trabalho e formação propedêutica, também tratada por Saviani (1989) e vista como um subsistema social por Mészáros (2005).

O ambiente de produção do trabalho em educação profissional também é a escola, ao que Nosella e Azevedo (2009) relembram tratar-se de uma instituição voltada à produção de conhecimento que é bastante recente, não descuidando de informar que nos diversos momentos da história da humanidade produziu-se educação, mas de forma ordenada e massiva ocorre apenas com a consolidação da instituição escola.

Mészarós (2005) e Kuenzer e Grabowski (2016) tratam da formação dentro do modo de produção capitalista, e sob a lógica da expropriação promovida pelo capital, especialmente em decorrência de mais-valia e da alienação do indivíduo, não se identificando adequadamente com seu estrato social, o que não lhe permite a busca conjunta de melhorias reais.

Ainda para Mészarós (2005), a forma como se ensina na sociedade capitalista é reprodutivista, embora os agentes que nesse ambiente atuam possam e de fato ajam de algum modo evitando uma totalidade alienante, o que resulta em conflitos de interesses constantes. 
Kuenzer e Grabowski (2016) chegam ao cenário da educação profissional que ainda é pautada pela dicotomia formação profissional e formação geral, somente superada pela concepção de politecnia que Saviani (1989) trabalha.

Para os autores já citados, o estágio atual do modo de produção implica socialmente na precarização das relações e dos direitos da classe trabalhadora, tendo por base um sistema de acumulação flexível, em que uma vertente fordista é abandonada pela "toyotista", exigindo uma formação que retira ainda mais da força de trabalho expropriada, pois não é devidamente retribuída em salários e benefícios.

Nesse sentido, a educação profissional aventada por Nosella e Azevedo (2009), bem como por Saviani (1989), é de natureza humanística e omnilateral ou integral, exigindo posturas crítico-reflexivas daqueles que a concretizam.

Na trajetória histórica da educação profissional no Brasil, Andrade (2014) informa que a origem da Rede Federal remonta à gestão do então presidente da Primeira República, Nilo Peçanha, o qual, substituindo Afonso Pena, inaugura as Escolas de Aprendizes e Artífices em 1909, de cunho eminentemente assistencialistas, pois voltadas a "desvalidos" e "desfavorecidos da fortuna", atribuindo-lhes formação que permitisse a fuga da vadiagem e/ou da criminalidade.

Tais escolas passaram por diversas alterações em sua nomenclatura e nas finalidades atribuídas à modalidade de ensino prestada, conforme representado na Figura 1:

Figura 1 - Linha do tempo da Rede Federal

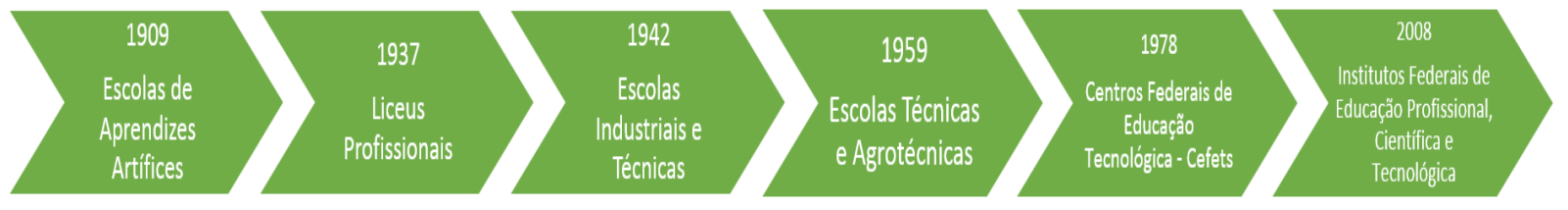

Fonte: Portal IFAC (2020).

Das Escolas de Aprendizes e Artífices à instituição da Rede Federal, formada por 38 Institutos Federais de Educação, Ciência e Tecnologia (IFs), 2 Centros Federais de Educação Tecnológica (Cefets), Escolas Técnicas Vinculadas às Universidades Federais e o Colégio Pedro II, o que se observa são constantes instabilidades de políticas fragmentárias e pontuais, ora baseadas na dicotomia de formação já tratada, que separava o ensino propedêutico do profissional, vedando ou, quando menos, dificultando a continuidade de estudos em nível elevado ao segundo grupo, ou outras formas de esvaziamento de sua atuação por captura e conflitos de interesses (ANDRADE, 2014).

Também com base em Ciavatta (2009 apud ANDRADE, 2014), são reveladas questões políticas internas à Rede Federal, como o caso da lei que criaria novos Cefets, do período do Governo Itamar Franco, decorrente da elevação de categoria de Escolas Técnicas; bem como as movimentações de entidades como os Cefets de Minas Gerais e do Rio de Janeiro, no sentido de buscarem a elevação à condição 
de Universidades Tecnológicas, como ocorreu com o Cefet do Paraná, atualmente a única universidade tecnológica do país.

Em continuidade, aponta Andrade (2014) que a Rede Federal sai de um processo de descontinuidade de expansão e vinculação a interesses empresariais, na gestão do ex-presidente Fernando Henrique Cardoso, em que retomada a dicotomia da formação profissional e propedêutica, agora com foco na formação para a empregabilidade, seguindo, na gestão do ex-presidente Luís Inácio Lula da Silva, para um processo de ressignificação e alteração de público-alvo.

Ainda conforme a autora, o atual cenário da Rede Federal é marcado por aumento quantitativo de mais de $150 \%$, se comparado ao total de unidades existentes desde 1909 até $2002^{1}$, e considerando a gestão do governo Lula, bem como agora há sinalização pela educação tecnológica como política de Estado, marcadamente em razão da interiorização do processo de formação tecnológica que visa a todas as camadas e grupos sociais, bem como chegando aos interiores do país e atuando consideravelmente na educação básica, por meio da formação integrada ao ensino médio.

Nesse contexto, a Rede Federal funciona por meio de autarquias federais no formato multicampi, atuando em todas as regiões e todos os estados do país, inclusive interior, levando educação de nível técnico (integrado, subsequente e concomitante), superior (graduação: tecnológica, licenciatura, bacharelado; e pósgraduação: lato e stricto sensu), bem como atuando na Educação de Jovens e Adultos (EJA) e com cursos para trabalhadores (Formação Inicial e Continuada FIC), o que acaba por requerer um conjunto orgânico de normas, unidades, diretrizes e agentes que se entendam dentro da missão institucional atribuída à Rede (BRASIL, 2008).

Em relação aos cursos técnicos, o Ministério da Educação (MEC) dispõe de um documento denominado Catálogo Nacional de Cursos Técnicos (CNCT), o qual é aprovado pelo respectivo ministro e orienta a oferta de cursos técnicos em todo o país, estando composto atualmente por 227 cursos agrupados em 13 eixos, em que são descritos elementos mínimos, como nomenclatura, carga horária, perfil do profissional de conclusão, infraestrutura mínima requerida, campo de atuação, possibilidades de verticalização da formação, dentre outros (MINISTÉRIO DA EDUCAÇÃO, 2016).

Dentro da concepção de formação profissional técnica de nível médio reside a convergência da teoria marxista e suas aplicações por Gramsci, Saviani, Ramos, Frigotto, Ciavatta, Kuenzer, Machado, dentre outros, conforme Moura (2013), em estudo que sintetiza as contradições e conflitos na busca por avanços nos percursos formativos de jovens de classes desfavorecidas em seus aspectos social, econômico, político, laboral etc.

O autor retoma questões históricas e dados de formação e faixas etárias para enfatizar a demanda por um ensino público que propicie expansão de capacidades, com ampla estrutura (docente, equipamentos, bibliotecas, laboratórios, instalações desportivas, preparação de atores, etc.), superação das dicotomias e desvantagens atualmente postas (MOURA, 2013).

\footnotetext{
1 Consta de subsite da Rede Federal na página virtual do MEC o total de 644 campi em funcionamento, sendo a informação disponível em 14 de agosto de 2020, no endereço http://redefederal.mec.gov.br/expansao-da-rede-federal.
} 
O ensino médio ofertado pela Rede Federal e tratado por Moura (2013) está previsto na Resolução CNE/CEB $n^{\circ}$ 6, de 20 de setembro de 2012, que define diretrizes curriculares nacionais para a educação profissional técnica de nível médio, tendo por princípios norteadores as articulações e indissociabilidades entre formações (profissional e geral), saberes, valores, disciplinas (interdisciplinaridade), contextos e formação, diversidades, colaboração e liberdades etc. (CÂMARA DE EDUCAÇÃO BÁSICA, 2012).

Essa formação humana integral perpassa por trabalho, ciência, tecnologia e cultura, em bloco formativo que compôs a escola unitária gramsciana, ao que o aporte dos recursos necessários depende de ampla e constante pressão social, vez que as diferenças (inclusive que limitam e inferiorizam) são benéficas às estruturas competitivas do modo de produção capitalista.

Pesquisa, trabalho, ciência, tecnologia e cultura passam a permear as formações, sejam em ensino médio técnico articulado ou subsequente, modalidades desenvolvidas nas unidades da Rede Federal, ao que o maior esforço consiste em resistência à transformação de tais políticas formativas em instrumento a favor do capital, da formação para mercados e manutenção de estruturas sociais duais ou desiguais.

Diante das características da RFEPCT, a educação jurídica nela prestada tem refletido, em sua essência, as bases da EPT e atendido os anseios do legislador? A questão norteadora será melhor debatida nas seções seguintes.

\section{Metodologia}

A pesquisa, enquanto procedimento sistematizado e racional, encontra delineamento em Gil (2007), com a caracterização de suas fases, cuja etapa problematização esteve relacionado com a busca de elementos teóricos e práticos para a caracterização da educação jurídica na EPT prestada pela Rede Federal, com uso de método indutivo, consubstanciado nas considerações baconianas sobre os fenômenos estudados de que tratam Gerhardt e Souza (2009), e, por fim, seguiu abordagem qualitativa, visando à compreensão de aspectos do objeto, seu contexto, ambientes e resultados (SILVEIRA; CÓRDOVA, 2009).

Para sua consecução, foram aplicados procedimentos de pesquisa bibliográfica e documental, conforme descritos por Silveira e Córdova (2009), de modo que, além de referenciais trabalhados em disciplinas obrigatórias do Programa de Mestrado Profissional em Educação Profissional e Tecnológica/Mestrado em Rede Nacional - ProfEPT, em número de oito, foram realizados levantamentos em sites de repositórios de publicações acadêmicas e de normativos da EPT e do EMI oferecido pela Rede Federal.

O estágio seguinte de levantamento de referências consistiu em busca de literatura em periódicos e revistas científicas por meio do uso dos descritores "educação jurídica" e "magistério jurídico" conjugados e/ou alternados com os descritores "metodologias ativas" e "educação profissional", ao que foram selecionados 4 novos referenciais, após identificação das abordagens e teorias a partir da leitura dos respectivos resumos.

A estes materiais foram somados 2 referenciais sobre os IFs e as políticas para EPT trabalhados em disciplinas eletivas do aludido mestrado, 3 pares de dissertação e 
produto educacional constantes dos sites Observatório ProfEPT e Portal EduCapes (para objetos educacionais) especificamente voltados para educação jurídica, 4 documentos de cunho normativo sobre a oferta da EPT, 1 referencial sobre Introdução ao Estudo do Direito e 3 referências de pesquisas sobre avaliação da qualidade da educação no Brasil, considerando planejamento nacional para educação, avaliações de larga escala e financiamento.

Ao todo, a etapa de revisão incluiu 7 artigos, 1 tese, 3 dissertações e respectivos produtos educacionais, 10 livros ou capítulos, 2 leis, 1 resolução e 1 documento normativo estruturador, cujos anos de publicação vão de 1980 (1) a 2020 (1), sendo a maioria dos exercícios de 2019 (3), 2018 (3), 2016 (3), 2015 (2), 2014 (3) e 2013 (2), ao que os mais antigos são de base teórica sobre aprendizagem significativa (1980), EPT, educação integral e politecnia (1989), e os demais abrangeram: avaliação da qualidade da educação brasileira, metodologias para o magistério jurídico, a educação profissional e tecnológica prestada pela Rede Federal e a educação jurídica enquanto possibilidade de formação cidadã, técnica e críticoreflexiva.

\section{Resultados e Discussão}

\section{Educação jurídica na Rede Federal de Educação Profissional e Tecnológica}

Gianezini (2014) conduziu pesquisa em que identificou algumas questões relevantes sobre a atuação de profissionais do Direito em cursos dos Institutos Federais de Educação, Ciência e Tecnologia situados Rio Grande do Sul, dentre as quais:

i) busca primeira por estabilidade no serviço público, em detrimento da construção de uma identidade e de cultura de valorização e prestígio pelo magistério enquanto carreira profissional (o que é questão nacional e não exclusiva da Rede Federal);

ii) dificuldade no entendimento do tipo de ensino a ser executado, haja vista não se tratar de formação de bacharéis em Direito; e

iii) ausência de formação pedagógica, ou ainda carência, de forma a suprir défices de formação dos profissionais bacharéis.

Trazidas questões histórico-conceituais e sobre a prática docente de profissionais de Direito no magistério dentro de um Instituto Federal, cabe tratar sobre o ensino ou a educação jurídica dentro da Rede Federal e com suas perspectivas e ferramentais, sempre vinculada a objetivos ligados à emancipação do ser humano e adequados à faixa etária e aos públicos atendidos, tendo por escopo de análise, nesta fase, trabalhos do ProfEPT.

Assim, as pesquisas e os produtos educacionais de Lamas (2019), Ferreira (2019) e Silva (2020), constantes dos repositórios Observatório ProfEPT e do Portal EduCapes, representam os mapeamentos de demanda e contribuições da educação jurídica dentro do EMI, com opções metodológicas consideradas aptas ao objetivo de cada trabalho. 
Foram temas ou conteúdos de ensino recorrentes aqueles relacionados com igualdade e direitos trabalhistas, ao que a primeira pesquisadora atribuiu ênfase ao tratamento dado a homens e mulheres na mesma profissão.

Em justificação, Lamas (2019) cita que tais conteúdos ou conhecimentos produzidos desencadeiam a prática efetiva da cidadania e contribuem para a formação de estado ético, em que a população seria politizada a partir do conhecimento ético-jurídico. Por sua vez, conhecimento este que geraria crítica sobre o papel social de cada indivíduo. Nesse cenário, desenvolve sequências didáticas para experiências interdisciplinares visando à formação omnilateral ou plena, e com apoio no uso de metodologias ativas.

Ferreira (2019), por sua vez, detalha a oportunidade de trabalhar conteúdos jurídicos no EMI de modo a contribuir com a formação cidadã e ética, com o desenvolvimento de produto educacional do tipo sequência didática e com apoio de livreto sobre tópicos importantes das legislações: Constituição Federal (conteúdos de direitos e garantias fundamentais); Código de Defesa do Consumidor (CDC); e Consolidação das Leis do Trabalho (CLT).

A autora informa adoção de metodologia ativa inspirada em Paulo Freire, com organização baseada em ação-reflexão-ação, com aulas expositivas e dialogadas, exibição de filmes trabalhados com roteiros, discussões em grupos com resposta a questionário e aplicação de atividades sobre livreto elaborado pela autora sobre os direitos selecionados.

Em seus resultados, para além das vantagens relacionados com aprendizado sobre direitos que serão essenciais para os jovens quando do ingresso no mundo do trabalho, a pesquisadora sinaliza pelo aproveitamento das temáticas em aplicações conjuntas por pares de disciplinas como Sociologia e Língua Portuguesa; História e Língua Portuguesa; Gestão Organizacional de Produção e de Pessoas e Língua Portuguesa; Filosofia e Língua Portuguesa.

Por fim, o último trabalho identificado dentre as pesquisas concluídas vinculadas ao ProfEPT é o de Silva (2020), que, numa trajetória semelhante de mapeamento sobre educação jurídica e sua justificativa, traz possibilidade de trabalhar conteúdos de noções de direito do trabalho com estudantes do EMI nos cursos técnicos do Instituto Federal de Educação, Ciência e Tecnologia de Alagoas (IFAL).

O pesquisador teve como aporte metodológico da pesquisa a pesquisa-ação, considerando o produto com construção coletiva executada com apoio de técnica de grupo focal composto também por estudantes voluntários que testaram, avaliaram, criticaram e sugeriram sobre o produto educacional jogo, enquadrado no subtipo serious game.

Para melhor caracterização de pesquisas, produtos, metodologias, resultados e avaliações de ganhos relacionados com a educação jurídica no contexto da EPT, elaborou-se o Quadro 1, com estruturação dos itens analisados por cada autor/pesquisador referenciado, que desenvolveu pesquisa vinculado ao ProfEPT: 


\begin{tabular}{|c|c|c|}
\hline \multicolumn{3}{|c|}{$\begin{array}{l}\text { IF e forma de execução: Projeto de Ensino na disciplina Sociologia, para o } 3^{\circ} \text { ano do Curso Técnico } \\
\text { Integrado em Zootecnia do IF Sudeste MG, Campus Rio Pomba. }\end{array}$} \\
\hline MA ou MI Usada & Principais resultados & Avaliação dos ganhos \\
\hline $\begin{array}{l}\text { Método construído com ênfase } \\
\text { na articulação das dimensões } \\
\text { fazer, pensar e sentir; na ação } \\
\text { coletiva e cooperativa; no } \\
\text { compromisso } \\
\text { transformação social; na na } \\
\text { consideração das experiências } \\
\text { de vida de estudantes; na } \\
\text { problematização da realidade; } \\
\text { na contextualização; no } \\
\text { diálogo, debate e análise de } \\
\text { problemas; na intervenção } \\
\text { social; na participação; na } \\
\text { afetividade; na investigação; } \\
\text { nas metodologias ativas; na } \\
\text { interdisciplinaridade } \\
\text { perspectivas de Cordiolli } \\
\text { (2006) apud Lamas (2019): } \\
\text { compartilhamento; ação } \\
\text { coletiva e práticas } \\
\text { colaborativas; aprendizagem } \\
\text { com pesquisa e diversidade de } \\
\text { fontes; produção de sínteses; e } \\
\text { socialização dos resultados e } \\
\text { retorno à comunidade. }\end{array}$ & $\begin{array}{l}\text { Estudantes consideram as } \\
\text { metodologias } \\
\text { empregadas como } \\
\text { novidade, ao que } \\
\text { destacaram elementos de } \\
\text { interatividade, pesquisa, } \\
\text { estímulo à curiosidade e à } \\
\text { percepção da alteridade. } \\
\text { Maior envolvimento de } \\
\text { estudantes, se comparado } \\
\text { com metodologia de aulas } \\
\text { expositivas, com diálogo, } \\
\text { escuta, respeito e } \\
\text { valorização da da } \\
\text { participação, o que elevou } \\
\text { a satisfação dos mesmos. }\end{array}$ & $\begin{array}{l}\text { A sequência aplicada e avaliada } \\
\text { sinalizou possibilidades de integração } \\
\text { de áreas (Direito e Sociologia), } \\
\text { visando a saber totalizante e a } \\
\text { percepção das relações dos } \\
\text { conhecimentos sob as perspectivas } \\
\text { de diferentes áreas. } \\
\text { Representa nova forma de atuação } \\
\text { de professores da área jurídica dentro } \\
\text { da EPT, contribuindo para a formação } \\
\text { cidadã e ética. }\end{array}$ \\
\hline \multicolumn{3}{|c|}{ Ferreira (2019) } \\
\hline \multicolumn{3}{|c|}{$\begin{array}{l}\text { IF e forma de execução: Aulas cedidas da disciplina Gestão Organizacional de Produção e de } \\
\text { Pessoas, ministrada nas turmas dos Cursos Técnicos Integrados em Automação Industrial e em } \\
\text { Química do IFSP, Campus Sertãozinho. }\end{array}$} \\
\hline MA ou MI Usada & Principais resultados & Avaliação dos ganhos \\
\hline $\begin{array}{lll}\text { Discussão em } & \text { grupo } & \text { e } \\
\text { apresentação de respostas } & \text { a } \\
\text { questionários. }\end{array}$ & $\begin{array}{l}\text { Interesse pelos temas } \\
\text { desconhecidos. }\end{array}$ & $\begin{array}{l}\text { Contribuição das sequências para a } \\
\text { formação para o exercício da } \\
\text { cidadania. }\end{array}$ \\
\hline \multicolumn{3}{|c|}{ Silva $(20$} \\
\hline \multicolumn{3}{|c|}{$\begin{array}{l}\text { IF e forma de execução: Estudantes voluntários do } 2^{\circ} \text { ano dos cursos técnicos integrados do Ifal, } \\
\text { Campus Marechal Deodoro. Seleção de } 5 \text { dos voluntários para integrarem grupo focal para } \\
\text { avaliação, críticas e sugestões ao protótipo do produto (serious game). }\end{array}$} \\
\hline MA ou MI Usada & Principais resultados & Avaliação dos ganhos \\
\hline $\begin{array}{lr}\text { Criação, } & \text { prototipagem, } \\
\text { testagem, correção e revisão } \\
\text { de jogo do tipo serious game, } \\
\text { visando aumento } r \text { da } \\
\text { motivação, facilitação da } \\
\text { aprendizagem significativa de } \\
\text { conteúdos transversais para a } \\
\text { EPT promovida pelo Ifal } \\
\text { (noções de direito do trabalho) } \\
\text { e diversão para os } \\
\text { estudantes/jogadores. }\end{array}$ & 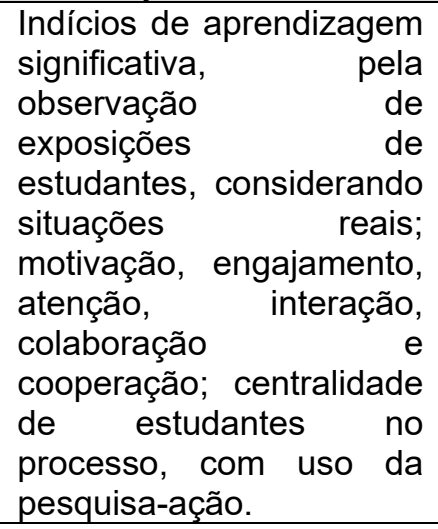 & $\begin{array}{l}\text { Oportunidade para tratar temas } \\
\text { transversais, especialmente noções } \\
\text { de direito do trabalho, que se } \\
\text { relacionam com a formação } \\
\text { profissional e cidadão do Ifal. } \\
\text { Vantagem de um jogo analógico pelo } \\
\text { resultado de interação e participação } \\
\text { de estudantes considerados } \\
\text { reservados ou pouco participativos, } \\
\text { bem como maior contato dos sujeitos } \\
\text { pela dinâmica do jogo, seja por parte } \\
\text { de jogadores ou estudantes que } \\
\text { assistiram e torceram por um deles. }\end{array}$ \\
\hline
\end{tabular}

Fonte: Elaborado pelos autores, a partir das referências analisadas.

MA - Metodologia ativa, MI - Metodologia inovadora.

Em análise da consolidação de itens das pesquisas e dos produtos, pode-se perceber a adoção de opções por sequências didáticas, enquanto unidades

L


caracterizadoras de uma determinada práxis pedagógica e com base em conceitos e estruturas trazidos por Zabala (1998), bem como de opção por jogo, compatibilizando-se com a metodologia ativa da gamificação, tratada por Bacich e Moran (2018).

Elementos como forma de execução, público-alvo e momentos serviram de parâmetro para a adoção de um ou outro formado de produto, sendo os dois primeiros aplicados em contexto de aulas e nos espaços da sala de aula, ao passo que o jogo consistiu em produto aplicado de modo desvinculado a disciplina, não obstante seu uso fosse compatível com componentes curriculares relacionados a artes e educação física ou mesmo enquanto metodologia ativa em qualquer das disciplinas em que as noções de direito do trabalho figuraram como temas transversais.

Assim, o trabalho de Silva (2020), dentre os analisados, traz um especial caso de aplicação de metodologia inovadora no ensino de tópicos de Direito do Trabalho a um público que sequer dispunha de tais componentes em sua formação técnica no EMI, a qual pode ser replicada em toda a Rede Federal, seja visando à introdução dos conteúdos por atividades lúdicas ou desportivas, ou com emprego dessas no âmbito das respectivas disciplinas jurídicas da área trabalhista.

Como demonstrado, o jogo teve etapas de cocriarão e revisão pelos próprios estudantes, ao que desenvolveu habilidades de atuação e participação até daqueles com perfis mais introspectivos. Tratou a experiência de um exemplo de como envolver o grupo (já que até os que assistiam aos jogos ficavam atentos e aprendiam) e gerar conhecimentos úteis para os espaços da vida fora do IF.

\section{Considerações finais}

O percurso da pesquisa permitiu perceber que o magistério jurídico demanda novas abordagens metodológicas, o que pode ter relação com estilos e perfis de gerações ou mesmo com revisão das habilidades e competências esperadas, bem como decorre da concepção que se tem de educação e dos processos de ensinoaprendizagem, agora sob a ótica da centralidade do sujeito cognoscente.

A primazia do aprendiz no processo ocorre em situações de cooperação e colaboração, no que metodologias ativas e inovadoras desempenham papel importante para a retenção da atenção e manutenção da motivação, também sendo incluídas atividades de pesquisa, compartilhamento, socialização e trabalho com entornos ou comunidades.

Nesse contexto, a EPT executada pelos IFs no âmbito do EMI com formação técnica demanda a inclusão de conteúdos para uma educação jurídica, pautada na ideia de formação autônoma, crítica e reflexiva dos estudantes para o mundo do trabalho e dentro dos demais eixos da vida humana (cultura, trabalho, ciência e tecnologia), agregando conteúdos para uma formação cidadã e ética (FERREIRA, 2019), incluindo direitos fundamentais e as diferenças de gêneros no âmbito das formações e áreas, a exemplo da Zootecnia (LAMAS, 2019), e preparando em direitos sociais para as atividades futuras dos egressos do ensino médio (SILVA, 2020), especialmente em relação ao direito do trabalho e as normas que regem as situações e relações, e conflitos delas decorrentes.

Ler


Para além da exploração de caminhos ou métodos, as pesquisas vinculadas ao ProfEPT sinalizam práticas educativas que tragam a educação jurídica enquanto item transversal essencial para a formação no EMI, e rediscutem seus ganhos e resultados, associando-os a novas posturas e oportunidades também para docentes da área e para a promoção da interdisciplinaridade.

Outras questões surgem da pesquisa ou como resultado de suas limitações, tais como caracterizar um magistério jurídico na Rede Federal sob o ponto de vista da atuação dos docentes da área do Direito, em paralelo com a necessidade de detalhar e investigar sobre as práticas educativas desenvolvidas no âmbito dos conteúdos de uma educação jurídica no âmbito dos IFs e demais instituições da citada rede, sejam eles trabalhados ou não por docentes da área jurídica.

Não obstante o primado da liberdade de cátedra e da autonomia didática, a educação ajustada às gerações e demandas de liberdade, participação e colaboração exigem um olhar crítico e progressista no bom emprego das metodologias tidas por diferenciadas das tradicionais, sejam elas metodologias ativas ou inovadoras, questões a serem melhor discutidas em estudos futuros com temas que envolvam o magistério jurídico, formação no âmbito da EPT e metodologias para uma educação condizente com o quadro evolutivo e o conjunto das tecnologias e de disseminação das informações da atualidade.

\section{Referências}

ALMEIDA, F.; SOUZA, A. L. D.; CAMARGO, S. B. Direito e realidade: desafios para o ensino jurídico. In: GHIRARDI, J. G.; FEFERBAUM, M. (org.). Ensino do direito em debate: reflexões a partir do $1^{\circ}$ Seminário Ensino Jurídico e Formação Docente. São Paulo: Direito GV, 2013.

AMARAL, E. A.; ROCHA, I. N. V. Metodologias ativas de ensino: percepções da aplicação no curso de Direito. In: ANDRADE JÚNIOR, J.; SILVA, N. L. C.; SOUZA, L. P. Metodologias ativas: práticas pedagógicas na contemporaneidade. Campo Grande: Editora Inovar, 2019, p. 97-112.

\section{ANDRADE, A. de F. B. Os Institutos federais de educação, ciência e}

tecnologia: uma análise de sua institucionalidade. Orientador: Bernardo Kipnis. 2014. 209 f. Tese (Doutorado em educação) - Universidade Federal do Brasília, Brasília, 2014.

AUSUBEL, D. P.; NOVAK, J. D.; HANESIAN, H. Psicologia educacional. Rio de Janeiro: Interamericana, 1980.

BACICH, L; MORAN, J. (org.). Metodologias ativas para uma educação inovadora: uma abordagem teórico-prática. Porto Alegre: Penso, 2018.

BRASIL. Lei $\mathbf{n}^{\circ}$ 11.892, de 29 de dezembro de 2008. Institui a Rede Federal de Educação Profissional, Científica e Tecnológica, cria os Institutos Federais de Educação, Ciência e Tecnologia, e dá outras providências. Disponível em: http://www.planalto.gov.br/ccivil_03/_Ato2007-2010/2008/Lei/L11892.htm. Acesso em: 27 abr. 2020.

CÂMARA DE EDUCAÇÃO BÁSICA. CONSELHO NACIONAL DE EDUCAÇÃO. Resolução CNE/CEB n $^{\circ}$ 6, de 20 de setembro de 2012. Define Diretrizes 
Curriculares Nacionais para a Educação Profissional Técnica de Nível Médio. Disponível em: http://ifc.edu.br/wpcontent/uploads/2017/09/Resolu\%C3\%A7\%C3\%A3o-CNE_CEB-06_2012.pdf. Acesso em: 27 abr. 2020.

FERRAZ JÚNIOR, T. S. Introdução ao Estudo do Direito. 9. ed. São Paulo: Atlas, 2016.

FERREIRA, G. G. Sequência didática com noções de direito da cidadania: contribuição para uma formação integral no ensino médio integrado. 2019. $130 \mathrm{f}$. Dissertação (Mestrado em educação profissional e tecnológica) - Instituto Federal de São Paulo, Sertãozinho, 2019.

GERHARDT, T. E.; SOUZA, A. C. Unidade 1 - Aspectos teóricos e conceituais. In: GERHARDT, T. E.; SILVEIRA, D. T. (org.). Métodos de pesquisa. Porto Alegre: Editora da UFRGS, 2009, p. 11-29.

GIANEZINI, K. Percepções e perspectivas docentes sobre o ensino jurídico em um Instituto Federal de Educação, Ciência e Tecnologia. Revista Ibero-Americana de Estudos em Educação, São Paulo, v. 9, n. 3, p. 729-737, 2014.

GIL, A. C. Como elaborar projetos de pesquisa. 4. ed. São Paulo: Atlas, 2007. KUENZER, A. Z.; GRABOWSK, G. A produção do conhecimento no campo da educação profissional no regime de acumulação flexível. Holos. Ano 32, v. 6. p. 22-32, 2016.

\section{LAMAS, C. B. O. Aproximações entre educação jurídica e ensino médio} integrado: proposta de sequências didáticas para uma formação cidadã e ética. 2019. 212 f. Dissertação (Mestrado em educação profissional e tecnológica) Instituto Federal do Sudeste de Minas Gerais, Rio Pomba, 2019.

MELO, C. E. S. Metodologias ativas de ensino e aprendizagem no curso de Direito: breves relatos de experiência de Ages. Revista de Graduação - USP Grad+, São Paulo, v. 3, n. 2, p. 107-112, jul. 2018.

MESQUISTA, S. S. A.; LELIS, I. A. O. M. Cenários do ensino médio no Brasil. Ensaio: avaliação e políticas públicas em educação, Rio de Janeiro, v. 23, n. 89, p. 821-842, out./dez. 2015. Disponível em:

https://www.scielo.br/pdf/ensaio/v23n89/1809-4465-ensaio-23-89-0821.pdf.

Acesso em: 27 abr. 2020.

MINISTÉRIO DA EDUCAÇÃO. Secretaria de Educação Profissional e Tecnológica. Catálogo Nacional de Cursos Técnicos. 3. ed. Brasília, 2016.

Disponível em: http://reitoria.ifpr.edu.br/wpcontent/uploads/2014/06/Cat\%C3\%A1logo-Nacional-de-Cursos-T\%C3\%A9cnicos3\%C2\%AA-edi\%C3\%A7\%C3\%A3o-2014.pdf. Acesso em: 26 jun. 2019.

MOURA, D. H. Ensino médio integrado: subsunção aos interesses do capital ou travessia para a formação humana integral? Educação e Pesquisa, São Paulo, v. 39, n. 3, p. 705-720, jul./set. 2013.

MOREIRA, M. A.; MASINI, E. F. S. Aprendizagem significativa: a teoria de David Ausubel. São Paulo: Centauro, 2001.

MÉSZÁROS, I. A educação para além do capital. Tradução de Isa Tavares. São Paulo: Boitempo, 2005. 
NOSELLA, P; AZEVEDO, M. L. N. A educação em Gramsci. In: FALCO, A. M. C. Sociologia da educação: múltiplos olhares. 2. ed. Maringá: EDUEM, 2009.

NOVAK, J. D.; CAÑAS, A. J. A teoria subjacente aos mapas conceituais e como elaborá-los e usá-los. Práxis Educativa, Ponta Grossa, v.5, n.1, p. 9-29, jan.-jun. 2010. Disponível em: http://www.periodicos.uepg.br. Acesso em: 26 jun. 2019.

PIERI, R. Retratos da educação no Brasil. INSPER Instituto de Ensino e Pesquisa: São Paulo, 2018. Disponível em: https://www.insper.edu.br/wpcontent/uploads/2018/10/Retratos-Educacao-Brasil.pdf. Acesso em: 27 abr. 2020.

SAVIANI, D. Sobre a concepção de politecnia. Rio de Janeiro: FIOCRUZ. Politécnico da Saúde Joaquim Venâncio, 1989.

SILVA, C. F. Construção de um serious game para abordagem de noções de direito do trabalho no contexto da educação profissional e tecnológica. 2020. 229 f. Dissertação (Mestrado em educação profissional e tecnológica) - Instituto Federal do Alagoas, Maceió, 2020.

SILVEIRA, D. T.; CÓRDOVA, F. P. Unidade 2 - A pesquisa científica. In: GERHARDT, T. E.; SILVEIRA, D. T. (org.). Métodos de pesquisa. Porto Alegre: Editora da UFRGS, 2009, p. 31-42.

ZABALA, A. A Prática Educativa: como ensinar. Porto Alegre: Artmed, 1998.

Recebido: $15 / 08 / 2020$

Aprovado: 09/12/2020

Como citar: UGALDE, N. A. P.; LEÃO, J. R. A.; FARIAS, C. S. Práticas educativas e metodologias inovadoras para uma educação jurídica no âmbito da Rede Federal de Educação Profissional e Tecnológica. Revista de Estudos e Pesquisa sobre Ensino Tecnológico (EDUCITEC), v. 6, e138820, 2020.

Direito autoral: Este artigo está licenciado sob os termos da Licença Creative CommonsAtribuição 4.0 Internacional.

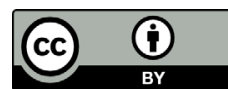

